\title{
Analysis of the prognostic impact of nestin expression in non-small cell lung cancer
}

\author{
Jozef Skarda ${ }^{\mathrm{a}}$, Zdenek Kolara ${ }^{\mathrm{a}}$, Maria Janikovaa ${ }^{\mathrm{a}}$ Lenka Radova ${ }^{\mathrm{b}}$, Vitezslav Kolekc, Edi Fridman ${ }^{\mathrm{d}}$, Juri Kopolovice
}

Background. Nestin is an intermediary filament protein, expressed in progenitor cells of neural and muscle origin and in activated endothelium. The expression of this protein in tumours can be associated with degree of differentiation, biological potential and/or neoangiogenesis.

Aims. The aim of this study was to examine the immunohistochemical expression of nestin in primary non-small cell lung carcinomas (NSCLC) and to determine its prognostic significance.

Methods. Immunohistochemical detection of nestin was carried out on tissue microarrays constructed from 114 formalin-fixed and paraffin-embedded NSCLC samples. These included 78 squamous cell carcinomas and 37 adenocarcinomas. Expression of nestin was also analysed in 35 primary tumour independent NSCLC brain metastasis. The $\mathrm{H}$-score and degree of nestin positive microvascularisation were determined. Both parameters correlated with the clinicopathological characteristics including disease-free and overall survival.

Results. We demonstrated that expression of nestin is not significantly higher in tumour cells of adenocarcinomas than in sqamous cell carcinomas despite the fact that adenocarcinomas were more frequently positive $(P \leq 0.30)$. On the other hand, nestin positivity and nestin positive neovascularisation were significantly more often found in stage IIla tumours than tumours in stages I and II $(P \leq 0.04, P \leq 0.02)$. Nestin expression was also significantly higher in brain metastases of squamous cell carcinomas than brain metastases of adenocarcinomas $(P \leq 0.003)$. The expression of nestin, in general, did not significantly correspond to disease-free or overall survival.

Conclusion. Nestin expression in NSCLCs is associated with poorer prognosis and with greater nestin-positive microvessel density.

Key words: nestin, non-small cell lung cancer, brain metastasis, immunohistochemistry, prognosis

Received: August 2, 2011; Accepted with revision: February 29, 2012; Available online: June 1, 2012 http://dx.doi.org/10.5507/bp.2012.036

\author{
${ }^{a}$ Department of Clinical and Molecular Pathology, Faculty of Medicine and Dentistry, Palacky University Olomouc, Czech Republic \\ ${ }^{b}$ Department of Pediatrics, Faculty of Medicine and Dentistry, Palacky University Olomouc \\ 'Department of Tuberculosis and Respiratory Diseases, Faculty of Medicine and Dentistry, Palacky University Olomouc \\ ${ }^{d}$ Department of Pathology, The Chaim Sheba Medical Center and Sackler School of Medicine, Tel Aviv University, Tel Aviv, Israel \\ ${ }^{e}$ Department of Pathology, Hadassah Medical School, Hebrew University, Jerusalem, Israel \\ Corresponding author: Jozef Skarda, e-mail:jojos@email.cz
}

\section{INTRODUCTION}

Nestin belongs to a class VI intermediate filament protein originally found in neuroepithelial stem cells and neural cells ${ }^{1}$. Nestin forms intermediate filament bundles with vimentin by copolymerization in neuroepithelial cells ${ }^{2}$. Nestin mRNA is expressed at a high level in the cerebrum of developing rat embryos on the 15 th prenatal day, its level decreases toward the 12th postnatal day, and disappears from the 18th postnatal day when it reaches adult levels ${ }^{1}$. High levels of nestin expression have been detected outside the nervous tissue in activated endothelium $^{3,4}$, the endothelium of pancreatic vessels, reactive astroglial cells, oligodendroglial cells, Sertoli's cells, hair follicle cells, stellate cells, pericytes, myoepithelial cells and odontoblasts ${ }^{5-12}$.

Nestin is also present in skeletal muscle progenitors, cardiac muscle progenitors, infarcted myocardium, and a large number of neoplasms ${ }^{13-15}$.
Tumour angiogenesis is an important factor for the growth and metastasis of human neoplasms. The degree of tumour angiogenesis is associated with clinical outcome and with tumour aggressiveness in general ${ }^{16-18}$. Above all, tumour angiogenesis is essential for the establishment of metastases in distant organs $\mathrm{s}^{19}$. A possible explanation of this metastatic mechanism is that an increase in the number of tumour vessels increases the chances for tumour cells to enter the circulation, and newly formed vessels or capillaries have leaky and weak basement membranes, through which tumour cells can penetrate more easily than through the basement membranes of normal mature vessels ${ }^{20}$. Thus, patients with highly vascularized tumours are significantly more likely to die than those with less vascularized tumours. Angiogenesis in malignant neoplasms, as measured in terms of microvessel density (MVD), has been reported to correlate with clinicopathological status and survival of several carcinomas such as breast, ovarian, prostatic, oesophageal, gastric, colorectal, cervical carci- 
noma and malignant melanoma ${ }^{16,17,21-29}$. Despite studies on the prognostic relevance of microvessel density in NSCLC (ref. ${ }^{30-34}$ ), the significance of nestin expression in NSCLC vessels remains unclear.

The expression of nestin in tumour cells can be associated with the degree of tumour differentiation, the invasive and metastatic potential of the tumour and/or degree of neoangiogenesis. Immunohistochemical detection of nestin can therefore not only be important for classification of tumours, but also for their prognostic assessment ${ }^{15}$. Some studies suggest that nestin may play a role in the regulation of cell proliferation, survival and differentiation ${ }^{35,36}$.

The expression of nestin in NSCLC cells was recently examined by Chen and co-workers ${ }^{34}$, but, in our opinion, extrapolation of their results is controversial, since these authors did not report whether the studied patients underwent preoperative radiotherapy and/or chemotherapy, and since they did not stratify patients according to tumour stage. Another recent paper on nestin expression in NSCLC described significantly higher expression of nestin in lymph node metastasis, in squamous cell carcinomas, in carcinomas with poorer differentiation, with vascular and lymphatic invasion and poorer prognosis, as well as with increased probability to $\mathrm{die}^{37}$. Thus, the aim of this study was to more precisely analyse immunohistochemical expression of nestin in cells of primary NSCLC, in intratumoral vessels and in brain metastasis in relation to important clinicopathologic characteristics such as sex, age, presence of metastasis, histological type, stage, grade of differentiation, disease-free and overall survival.

\section{MATERIALS AND METHODS}

\section{Patients and tissues}

Tissue microarrays were constructed from 114 formalin-fixed and paraffin-embeded non-small cell lung cancer samples from the tissue banks of the Department of Pathology, Palacky University and University Hospital, Olomouc and Israel. The cohort consisted of 78 sqamous cell carcinomas and 37 adenocarcinomas. Adenocarcinomas and sqamous cell carcinomas were further subdivided into poorly differentiated (grade 3) and well-differentiated (grade 1 and 2) subtypes according to World Health Organisation recommendations. Stage of tumours based on the TNM classification was determined according to the recommended guidelines. Lymph node metastases were found in 68 examined NSCLC patients. Expression of nestin was also determined in 35 primary NSCLC independent brain metastases. All tumour samples with the exception of brain metastases were obtained through surgery before the start of neoadjuvant or adjuvant chemotherapy. The study was approved by the local institutional ethics committees. Detailed characteristics of patient groups and their relation to nestin expression and nestin-positive vascularisation are shown in Tables $1,2$.

\section{Immunohistochemistry}

The detection of nestin was carried out by indirect immunohistochemistry on tissue microarray sections, utilising a commercially available anti-nestin monoclonal antibody (clone 10C2, cat. no MAB5326, Chemicon International, USA). After deparaffinization, endogenous peroxidase activity was blocked by incubation with $0.3 \%$ hydrogen peroxide in methanol for $30 \mathrm{~min}$. Sections were pretreated in a microwave generator for $15 \mathrm{~min}$ in $10 \mathrm{mM}$ citrate buffer ( $\mathrm{pH}$ 6.0) and incubated with the anti-nestin antibody diluted 1:200 in PBS containing 1\% BSA, for $60 \mathrm{~min}$ at room temperature. Nestin was visualized by a secondary staining system (EnVision, Dual Link SystemHRP, cat. No. K4061, Dako North America Inc., USA) using diaminobenzidine tetrahydrochloride as substrate. The sections were counterstained with hematoxylin, dehydrated and mounted in Canadian balsam. Negative controls included sections where the staining with the primary antibody was omitted in the staining procedure. The positivity of blood vessel endothelium was considered to be a positive control.

\section{Evaluation and statistical analysis}

The nestin positivity was assessed using an H-score (0 - none positivity, 1 - weak positivity, 2 - moderate positivity and 3 - strong positivity multiplied by $\%$ of positive cells), and the degree of nestin positive vascularisation (determined semiqantitatively in areas of the most prominent vascularization - 1 - weak, 2 - moderate and 3 - strong) were determined according to the consensual methodology ${ }^{18}$. Both parameters were correlated with disease-free and overall survival and with other clinicopathological characteristics. The H-scores and grade of microvascularizations were calculated as an average of the values obtained by two independent experienced investigators. The data were analysed using the nonparametric Mann-Whitney test. Fisher's exact test was used to compare the number of positive and negative cases within individual groups. Associations of these parameters with disease free and overall survival were analysed by the Kaplan-Meier method. The data were processed with SPSS statistical software version 15 (SPSS Inc., Washington, USA). The values $P \leq 0.05$ were considered significant.

\section{RESULTS}

The results showed that the expression of nestin was not significantly higher in the tumour cells of adenocarcinomas than in sqamous cell carcinomas despite the more frequently found nestin-positivity for adenocarcinomas. We used two thresholds of positivity: first where analysed tumours exhibited an $\mathrm{H}$-index higher than 0 and second where the H-index was higher than 10 . The differences in both cases were not significant $(P \leq 0.25$, resp. $P \leq 0.30)$. These results are summarized in Table 3.

As it is shown in Table 4, the nestin positivity and nestin positive neovascularisation were demonstrated 

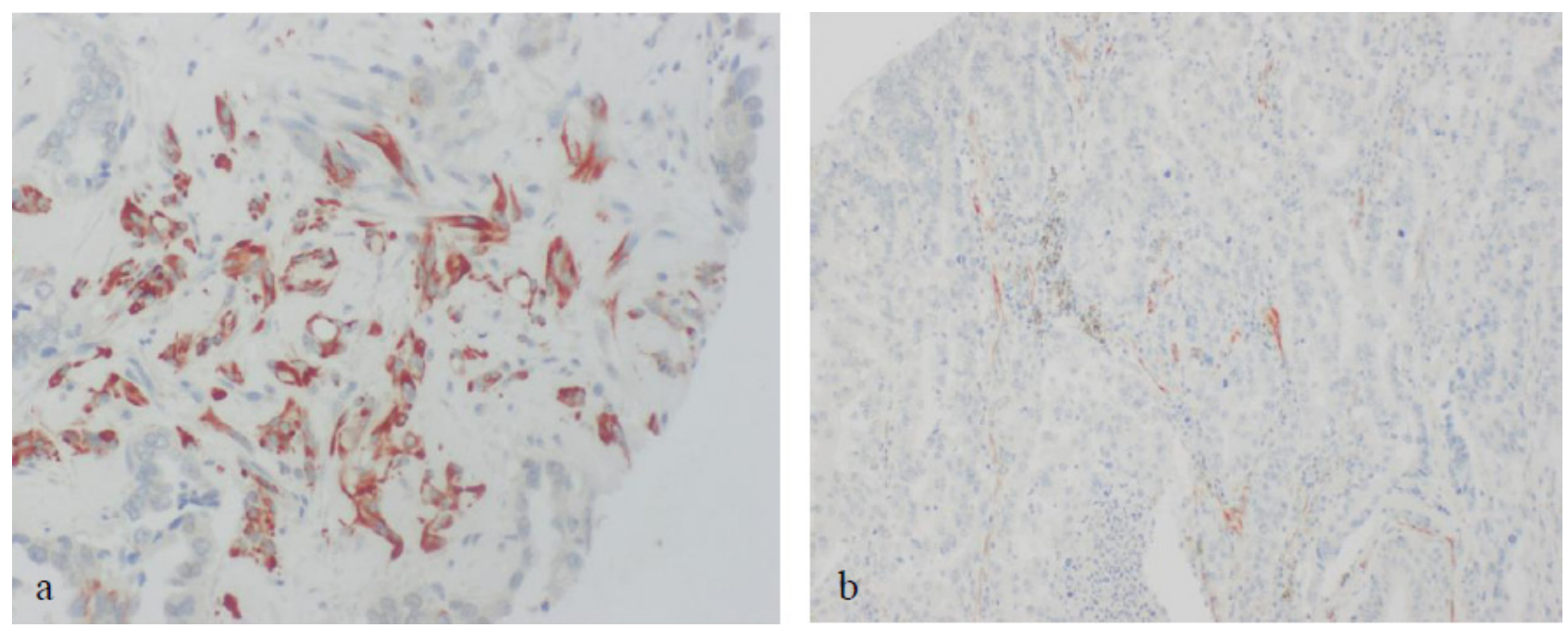

Fig. 1. Comparison of typical nestin positive vascularisation in brain metastasis (a) and primary tumour (b).
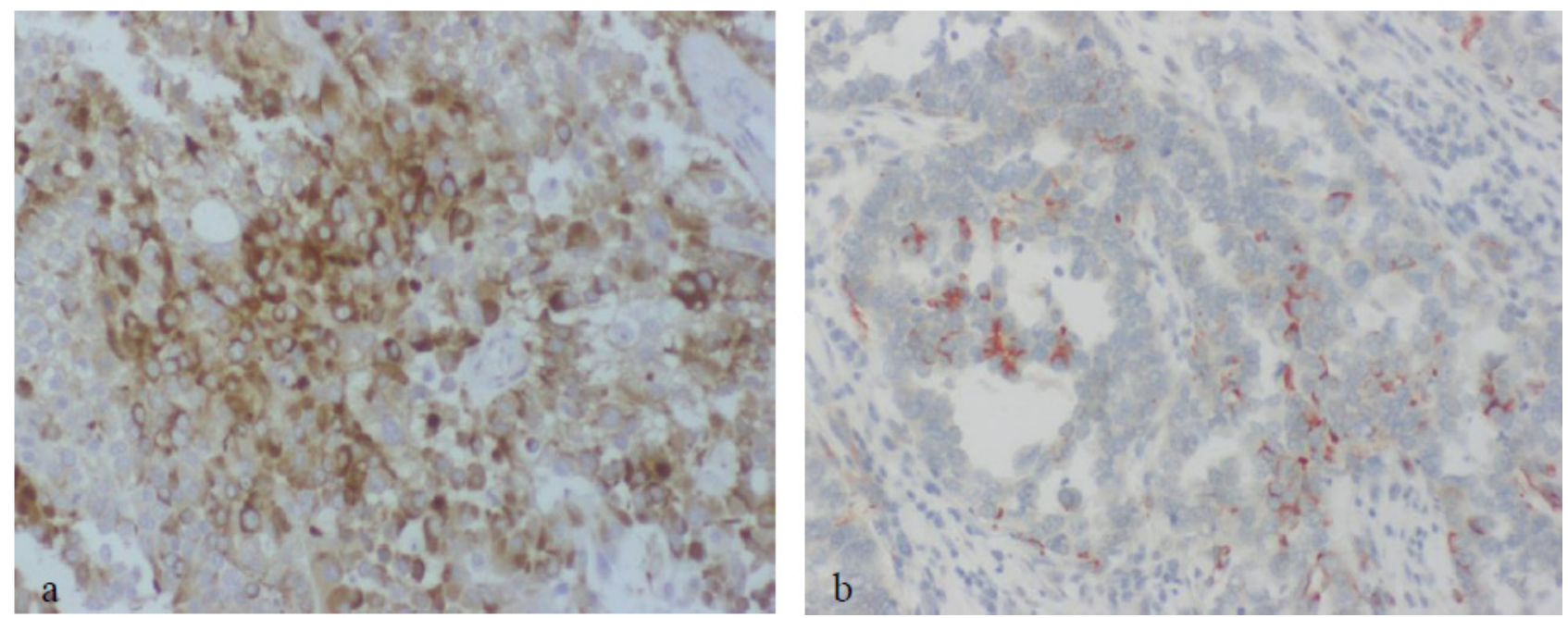

Fig. 2. Comparison of nestin expression in metastasis of squamous cell carcinoma (a) and metastasis of adenocarcinoma (b).
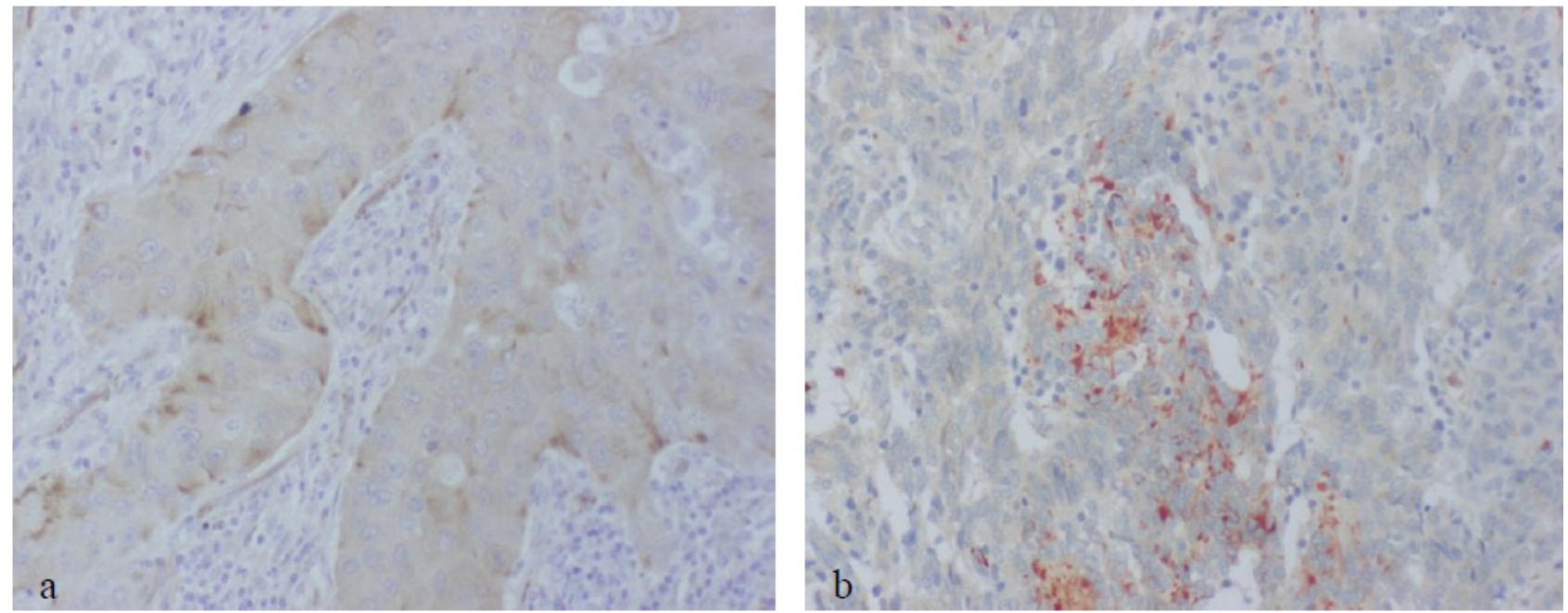

Fig. 3. Comparison of typical nestin expression in primary squamous cell carcinoma (a) and brain metastasis of squamous cell carcinoma (b). 

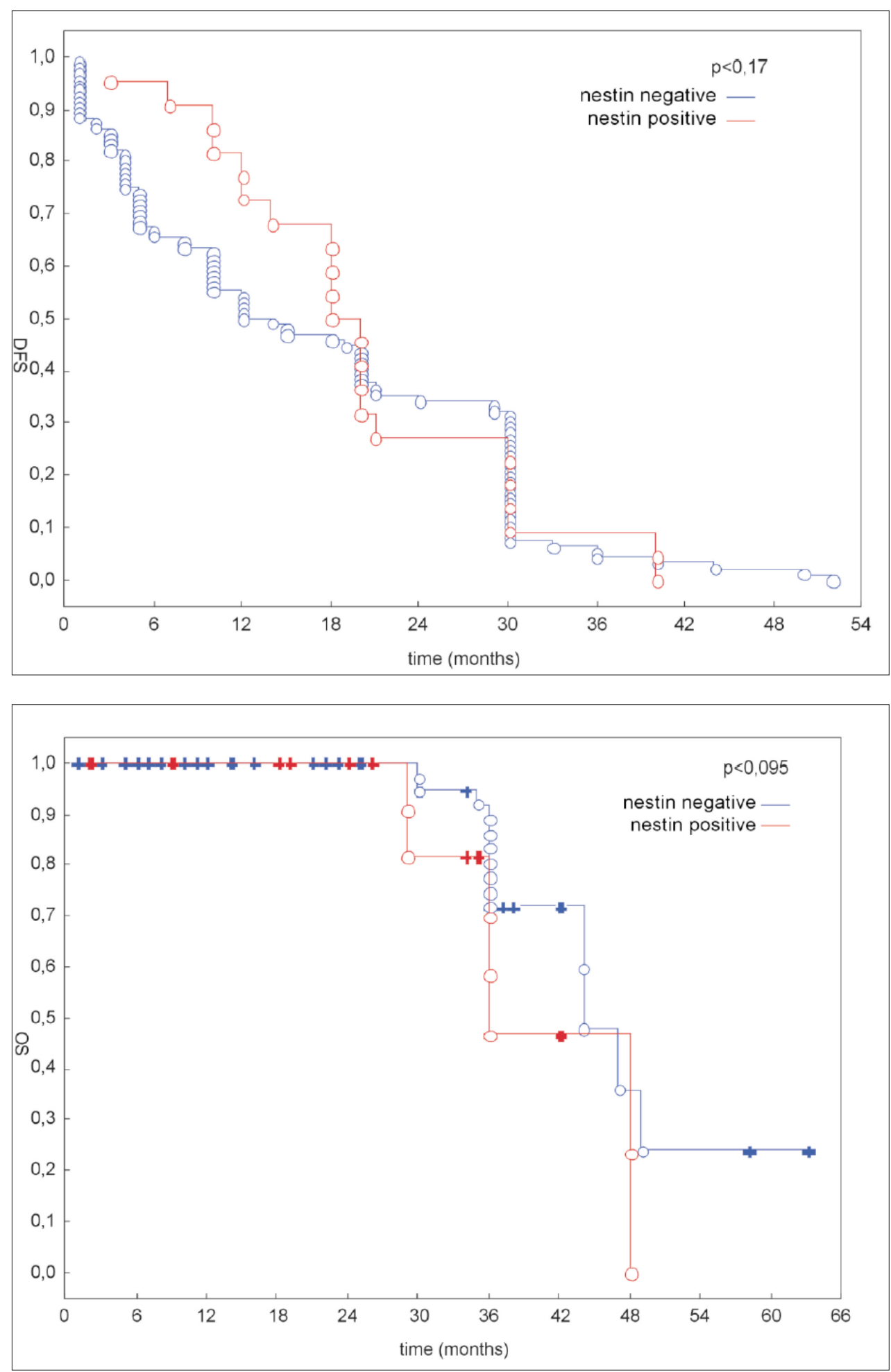

Fig. 4. Disease-free survival in patients with nestin positive and negative NSCLC.
Fig. 5. Overall survival in patients with nestin positive and negative NSCLC. significantly more often in tumours of stage IIIa than in tumours of stages I and II $(P \leq 0.04, P \leq 0.02)$. We found no significant differences between stages when mean and median $\mathrm{H}$-indexes were compared.

We found a significantly higher expression of nestin in brain metastases of squamous cell carcinomas than in brain metastases of adenocarcinomas ( $P=0.003$, Table 5) and generally the mean neovascularisation in brain metastases was more intensive than in primary tumours (Fig. 1). Moreover, we observed a higher percentage of nestin-positive cells surrounding tumour cell nests in the brain metastases of sqamous cell carcinomas but not in the metastases of adenocarcinomas (Fig. 2,3).

Kaplan-Meier's curves of disease-free and overall survival showed no significant correlations with nestin expression in general, and/or with different histological subtypes, different degree of differentiation of primary tumours and brain metastases. However, some interesting trends were found. The disease-free interval was evidently longer for the first 18 months in patients with 

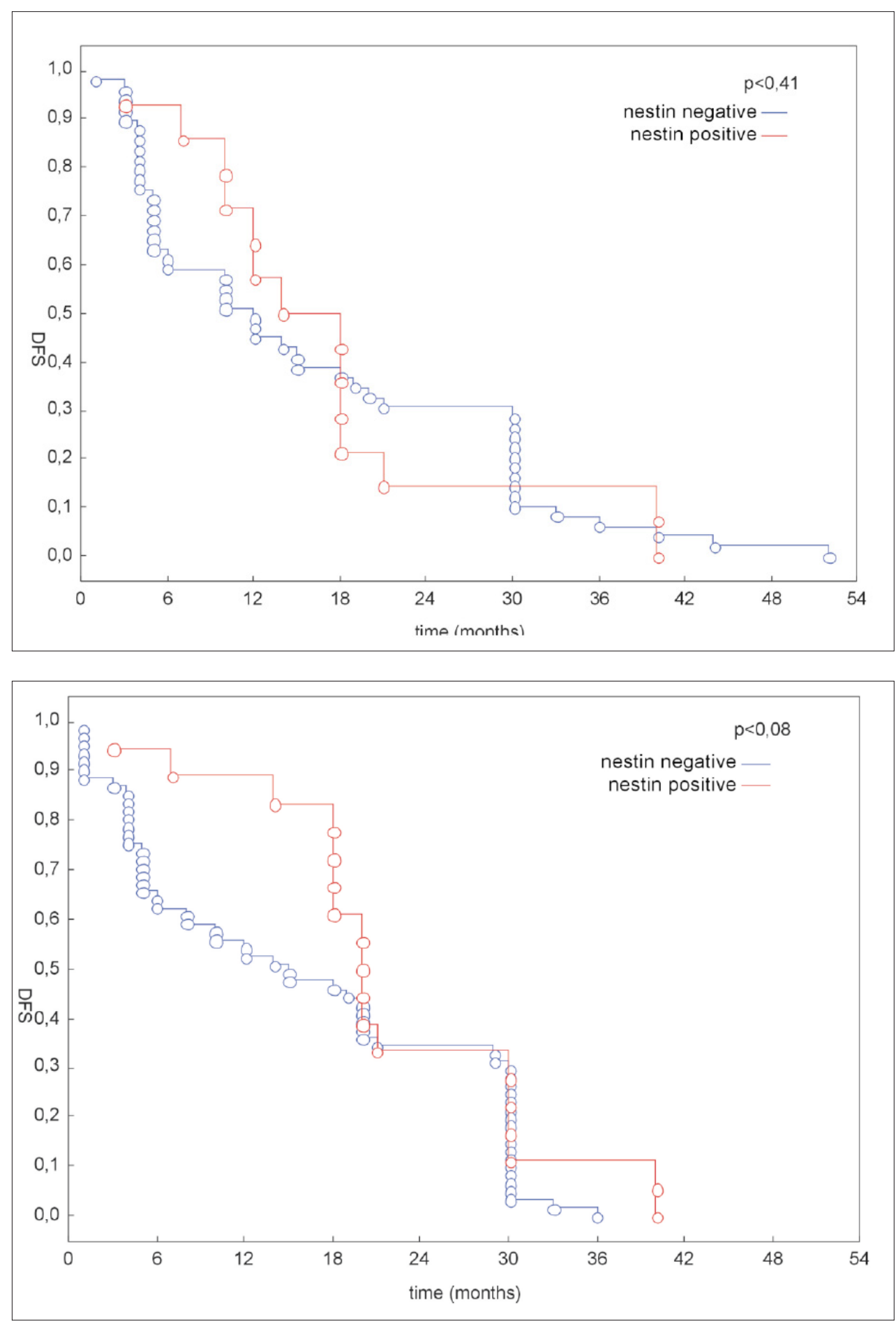

Fig. 6. Disease-free survival in stage IIIA of nestin positive NSCLC.

Fig. 7. Disease-free survival with sqamous cell nestin positive NSCLC. nestin positive NSCLC. On the other hand, overall survival was shorter for patients with nestin positive NSCLC (Fig. 4,5). The disease-free interval was also longer for the first 18 months in patients with stage IIIa nestin-positive NSCLC (Fig. 6) and in patients with squamous cell nestin-positive carcinoma (Fig. 7).

\section{DISCUSSION}

We found no significantly different expression of nestin between histological subtypes of NSCLC, although adenocarcinomas were more often nestin-positive. This result does not resolve the discordance between the published study of Chen and co-workers ${ }^{34}$, who described significantly higher expression of nestin in adenocarcinomas, and Ryuge and co-workers ${ }^{37}$ who reported higher positivity in squamous cell carcinoma. The differences could be explained by the use of different antibodies. The antibody used in our analysis was not identical either but it probably recognized a similar epitope of nestin as the antibody used by Ryuge and co-workers, because it produced only cytoplasmic immunostaining in tumour cells. The antibody used by Chen and co-workers stained 
Table 1. Clinicopathological and histopathological characteristics of NSCLC patients and their relation to nestin expression (H-index) and nestin-positive vascularisation.

\begin{tabular}{lcccccc}
\hline & Total & $\begin{array}{c}\text { Nestin- } \\
\text { positive cases } \\
\text { (H-index>0) }\end{array}$ & $\%$ & $\begin{array}{c}\text { Mean } \\
\text { H-index }\end{array}$ & $\begin{array}{c}\text { Number of cases } \\
\text { with nestin-positive } \\
\text { vascularisation }\end{array}$ & $\%$ \\
\hline Number of patients & 114 & 40 & 35.1 & 65.98 & 9 & 8 \\
Male & 92 & 31 & 33.7 & 66.52 & 1 & 8.7 \\
Female & 23 & 10 & 43.5 & 35.40 & 6 & 4.5 \\
Squamous cell carcinoma & 79 & 23 & 29.1 & 52.70 & 6 & 7.6 \\
Grade I and II & 66 & 20 & 33.3 & 54.15 & 0 & 9.1 \\
Grade III & 13 & 3 & 23.1 & 43.30 & 3 & 0.0 \\
Adenocarcinoma & 36 & 19 & 52.8 & 88.42 & 1 & 8.6 \\
Grade I and II & 21 & 11 & 52.4 & 68.64 & 2 & 5.0 \\
Grade III & 15 & 8 & 52.3 & 115.60 & 2 & 13.3 \\
Brain metastases & 35 & 30 & 85.7 & 94.39 & & 5.7 \\
\hline
\end{tabular}

Table 2. Clinicopathological and histopathological characteristics of NSCLC patients and their relation to disease stage.

\begin{tabular}{lrrrr}
\hline & Total & Stage I & Stage II & Stage IIIa \\
\hline Number of patients & 114 & 31 & 27 & 56 \\
Male & 92 & 29 & 20 & 43 \\
Female & 22 & 2 & 7 & 13 \\
Age & 60.3 & 61.0 & 60.6 & 59.5 \\
Squamous cell carcinoma & 79 & 21 & 13 & 45 \\
Grade I and II & 66 & 18 & 13 & 35 \\
Grade III & 13 & 3 & 0 & 10 \\
Adenocarcinoma & 35 & 10 & 14 & 11 \\
Grade I and II & 20 & 3 & 9 & 4 \\
Grade III & 15 & & 4 & 8 \\
\hline
\end{tabular}

Table 3. Comparison of nestin expression in adenocarcinomas versus squamous cell carcinomas.

\begin{tabular}{cccccc}
\hline & $\mathrm{N}$ & \multicolumn{3}{c}{ H-index } \\
\cline { 3 - 6 } & & 0 & $>0$ & $0+\leq 10$ & $>10$ \\
\hline \multirow{2}{*}{ Adenocarcinoma } & 35 & 20 & 15 & 24 & 11 \\
& & $57.2 \%$ & $42.8 \%$ & $68.6 \%$ & $31.4 \%$ \\
Squamous cell c. & 54 & $68.4 \%$ & 25 & 63 & 16 \\
& & 74 & 40 & $79.8 \%$ & $20.2 \%$ \\
Total & 114 & $64.9 \%$ & $35.1 \%$ & $76.3 \%$ & 27 \\
p-value & & 0.25 & & & 0.30 \\
\hline
\end{tabular}

both the cytoplasmic and the nuclear nestin epitopes but according to the authors, most of the nestin positivity was located in the nuclei. In our study, we also found a significantly higher expression of nestin in brain metastases of squamous cell carcinomas than the metastases of adenocarcinomas. Unfortunately, we could not compare these results with nestin expression in relevant primary tumours. We described a higher ocurrence of nestin positive cells surrounding tumour cell nests which was observed in brain metastases of squamous cell carcinomas but not in metastases of adenocarcinomas. 
Table 4. Nestin expression and nestin-positive vascularisation in adenocarcinomas and squamous cell carcinomas as a whole in relation to stage of disease.

\begin{tabular}{lccccc}
\hline Number of cases & Total & Stage I & Stage II & Stage IIIa & $P$ \\
\hline Nestin-positive vascul. & 9 & 1 & 1 & 7 & 0.02 \\
Nestin-positive cases & 31 & 6 & 8 & 17 & 0.04 \\
Nestin H-index mean & 68.98 & 69.5 & 97.3 & 53.2 & 0.30 \\
Nestin H-index median & 90 & 90 & 93 & 60 & 0.54 \\
\hline
\end{tabular}

Compared stage I and II vs. stage IIIa

Table 5. Comparison of nestin expession in brain metastases of adenocarcinoma and squamous cell carcinoma.

\begin{tabular}{lcccccc}
\hline H-index & N & Minimum & Maximum & Median & Mean & Std. deviation \\
\hline Adenocarcinoma & 24 & 0 & 110 & 80 & 63.33 & 39.75 \\
Squamous cell carcinoma & 11 & 50 & 250 & 100 & 125.45 & 68.17 \\
\hline
\end{tabular}

Total number 35

$P \leq 0.003$

We hypothesise that these nestin-positive metastatic tumour cells may represent a pool of stem/progenitor populations of proliferating cells similar to those recently described in the basal/myoepithelial layer of the mammary gland and the basal epithelial breast cancer subtype ${ }^{12,38,39}$.

Currently, nestin is considered a marker of activated endothelium ${ }^{4}$. Also in fetal tissues, nestin is strongly expressed in endothelial cells during the vasculogenesis. However, nestin expression is down-regulated in the vasculature of postnatal and adult animals where it can be restricted only to newly formed blood vessels ${ }^{40}$. Significantly higher nestin positive vascularization in advanced NSCLC in stage IIIa than in stages I and II found in this study support our previous findings describing an increase in nestin-positive vascularization in less differentiated cancers ${ }^{15}$. Microvessel density (MVD) is also considered an independent prognostic marker for different invasive carcinomas ${ }^{21-23,25-31}$. Thus a higher MVD of nestin positive blood vessels may be responsible for higher risk of recurrence and metastasis of non-small cell lung cancers.

In this study we found that nestin expression seems to be associated with poorer prognosis since it is significantly more expressed in tumours of higher stage as well as with greater nestin-positive microvessel density. These results are in agreement with previous reports concerning NSCLC although, to date, no description of a significant association of nestin-expression with stage of NSCLC has been published. On the other hand, no association with tumour grade was confirmed. This is not in agreement with either Chen or Ryuge findings $\mathrm{s}^{34,37}$. The fact that we found no significant association of nestin expression with disease-free and overall survival is in contrast with common assumptions. Perhaps, a higher degree of neoangiogenesis during the initial disease stages can be exploited to deliver a larger dose of chemotherapeutics to the tumour during a certain period of its growth. Our finding of better disease-free survival during the first 18 months of disease supports this idea. Although the precise function of nestin remains to be elucidated, several studies suggest that it may play a role in the regulation of cell proliferation, survival and differentiation ${ }^{35,36}$. From the data available, the role of nestin in the regulation of migration and invasion of NSCLC cells also cannot be excluded.

\section{ACKNOWLEDGEMENTS}

This study was supported in part by grants MSMT 61875921, IGA MZ CR 10259-3, 9959-3 and by internal grant of Palacky University 91110281 and project Biomedicine for regional development and human resources (BIOMEDREG) C.1.05/2.100/01.0030.7.

\section{REFERENCES}

1. Lendahl U, Zimmerman LB, McKay RD. CNS stem cells express a new class of intermediate filament protein. Cell 1990;60:585-95.

2. Marvin MJ, Dahlstrand J, Lendahl U, McKay RD. A rod end deletion in the intermediate filament protein nestin alters its subcellular localization in neuroepithelial cell sof transgenic mice. J Cell Sci 1998;111:1951-61.

3. Sugawara K, Kurihara H, Negishi M, Saito N, Nakazato Y, Sasaki T, Takeuchi T. Nestin as a marker for proliferative endothelium in gliomas. Lab Invest 2002;82:345-51.

4. Mokry J, Cizkova D, Filip S, Ehrmann J, Osterreicher J, Kolár Z, English D. Nestin expression by newly formed human blood vessels. Stem Cells Dev 2004;13:658-64.

5. Almazan G, Vela JM, Molina-Holgado E, Guaza C. Reevaluation of nestin as a marker of oligodendrocyte lineage cells. Microsc Res Tech 2001;52:753-65.

6. Krum JM, Rosenstein JM. Transient coexpression of nestin,GFAP, and vascular endothelial growth factor in mature reactive astroglia following neural grafting or brain wounds. Exp Neurol 1999;160:34860. 
7. Frojdman K, Pelliniemi LJ, LendahI U, Virtanen I and Eriksson JE. The intermediate filament protein nestin occurs transiently in differentiating testis of rat and mouse. Differentiation 1997;61:243-9.

8. Amoh Y, Li L, Yang M, Moossa AR, Katsuoka K, Penman S, Hoffman RM. Nascent blood vessels in the skin arise from nestin-expressing hair-follicle cells. Proc Natl Acad Sci USA 2004;101:13291-5.

9. Lardon J, Rooman I, Bouwens L. Nestin expression in pancreatic stellate cells and angiogenic endothelial cells. Histochem Cell Biol 2002;117:535-40.

10. Klein T, Ling Z, Heimberg H, Madsen OD, Heller RS, Serup P. Nestin is expressed in vascular endothelial cells in the adult human pancreas. J Histochem Cytochem 2003;51:697-706.

11. Terling C, Rass A, Mitsiadis TA, Fried K, Lendahl U, Wroblewski J. Expression of the intermediate filament nestin during rodent tooth development. Int J Dev Biol 1995;39:947-56.

12. Kolar Z, Ehrmann J. Jr, Turashvili G., Bouchal J., Mokrý J. A nove myoepitelial/ progenitor cell marker in the breast? Wirchovs Arch 2007; 450:607-9.

13. Sejersen T, Lendahl U. Transient expression of the intermediate filament nestin during skeletal muscle development. J Cell Sci 1993;106:1291-1300.

14. El-Helou V, Dupuis J, Proulx C, Drapeau J, Clement R, Gosselin H, Villeneuve L, Manganas L, Calderone A. Resident nestin+ neural-like cells and fibers are detected in normal and damaged rat myocardium. Hypertension 2005;46:1219-1300.

15. Ehrmann J, Kolar Z, Mokry J. Nestin as a diagnostic and prognostic marker: immunohistochemical analysis of its expression in different tumours. J Clin Pathol 2005;58:222-3.

16. Hansen S, Grabau DA, Rose C, Bak M, Sorensen FB. Angiogenesis in breast cancer: a comparative study of the observer variability of methods for determining microvessel density. Lab Invest 1998;78:1563-73.

17. Schoell WM, Pieber D, Reich O, Lahousen M, Janicek M, Guecer F, Winter R. Tumor angiogenesis as a prognostic factor in ovarian carcinoma: quantification of endothelial immunoreactivity by image analysis. Cancer 1997;80:2257-62.

18. Vermeulen PB, Gasparini G, Fox SB. Quantification of angiogenesis in solid human tumours: an international consensus on the methodology and criteria of evaluation. Eur J Cancer 1996;32A:2474-84.

19. Tomisaki S, Ohno S, Ichiyoshi Y, Kuwano H, Maehara Y, Sugimachi K. Microvessel quantification and its possible relation with liver metastasis in colorectal cancer. Cancer 1996;77:1722-8.

20. Liotta LA, Saidel MG, Kleinerman J. The significance of hematog enous tumor cell clumps in the metastatic process. Cancer Res 1976;36:889-94.

21. Wakui S, Furusato M, Itoh T, Sasaki H, Akiyama A, Kinoshita I, Asano $\mathrm{K}$, Tokuda T, Aizawa S, Ushigome S. Tumour angiogenesis in prostatic carcinoma with and without bone marrow metastasis: a morphometric study. J Pathol 1992;168:257-62.

22. Tanigawa N, Matsumura M, Amaya H, Kitaoka A, Shimomatsuya T, Lu C, Muraoka R, Tanaka T. Tumor vascularity correlates with the prog nosis of patients with esophageal squamous cell carcinoma. Cancer 1997;79:220-25.

23. Tanigawa N, Amaya H, Matsumura M, Shimomatsuya T. Association of tumour vasculature with tumour progression and overall survival of patients with non-early gastric carcinomas. Br J Cancer 1997;75:566-71.
24. Kim HS, Kang HS, Messam CA, Min KW, Park CS. Comparative evaluation of angiogenesis in gastric adenocarcinoma by nestin and CD34. Appl Immunohistochem Mol Morphol 2002;10:121-7.

25. Tomoda M, Maehara Y, Kakeji Y, Ohno S, Ichiyoshi Y, Sugimachi K. Intratumoral neovascularization and growth pattern in early gastric carcinoma. Cancer 1999;85:2340-6.

26. Takahashi Y, Tucker SL, Kitadai Y, Koura AN, Bucana CD, Cleary KR, Ellis LM. Vessel counts and expression of vascular endothelial growth factor as prognostic factors in node-negative colon cancer. Arch Surg 1997;132:541-6.

27. Uzzan B, Nicolas P, Cucherat M, Perret GY. Microvessel density as a prognostic factor in women with breast cancer: a systematic review of the literature and meta-analysis. Cancer Res 2004;64:2941-55.

28. Vieira SC, Zeferino LC, Da Silva BB, Aparecida Pinto G, Vassallo J, Carasan GA, De Moraes NG. Quantification of angiogenesis in cervical cancer: a comparison among three endothelial cell markers. Gynecol Oncol 2004;93:121-4.

29. Srivastava A, Laidler P, Hughes LE, Woodcock J, Shedden EJ. Neovascularization in human cutaneous melanoma: a quantitative morphological and Doppler ultrasound study. Eur J Cancer Clin Oncol 1986;22:1205-9.

30. Macchiarini P, Fontanini G, Hardin MJ, Squartini F, Angeletti CA. Relation of neovascularisation to metastasis of non-small-cell lung cancer. Lancet 1992;340:145-6.

31. Meert AP, Paesmans M, Martin B, Delmotte P, Berghmans $T$, Verdebout JM, Lafitte JJ, Mascaux C, Sculier JP. The role of microvessel density on the survival of patients with lung cancer: a systematic review of the literature with meta-analysis. Br J Cancer 2002;87:694701.

32. Yano T, Tanikawa S, Fujie T, Masutani M, Horie T. Vascular endothelia growth factor expression and neovascularisation in non-small cell lung cancer. Eur J Cancer 2000;36:601-9.

33. Offersen BV, Pfeiffer P, Hamilton-Dutoit S, Overgaard J. Patterns of angiogenesis in nonsmall-cell lung carcinoma. Cancer 2001;91:15009.

34. Chen $Z$, Wang $T$, Luo $H$, Lai $Y$, Yang $X$, Li F, Lei Y, Su C, Zhang $X$, Lahn B T, Xiang A P. Expression of nestin regarding to lymf node metastasis and lymphangiogenesis in non-small cell lung cancer patiens. Human Pathol 2010;41:737-44.

35. Bieberich E, MacKinnon S, Silva J, Noggle S, Condie BG. Regulation of cell death in mitotic neural progenitor cells by asymmetric distribution of prostate apoptosis response 4 (PAR-4) and simultaneous elevation of endogenous ceramide. J Cell Biol 2003;162:469-79.

36. Sahlgren CM, Mikhailov A, Vaittinen S, Pallari HM, Kalimo H, Pant HC, Eriksson JE. Cdk5 regulates the organization of nestin and its association with p35. Mol Cell Biol 2003;23:5090-106.

37. Ryuge $S$, Sato $Y$, Wang GQ, Matsumoto $T$, Jiang SX, Katono $K$, Inoue $\mathrm{H}$, Satoh Y, Masuda N. Prognostic significance of nestin expression in resected non-small cell lung cancer. Chest 2010;139:862-9.

38. Li H, Cherukuri P, Li N, Cowling V, Spinella M, Cole M, Godwin AK, Wells W, DiRenzo J. Nestin is expressed in the basal/myoepithelia layer of the mammary gland and is a selective marker of basal epithelial breast tumors. Cancer Res 2007;67:501-10.

39. Parry S, Savage K, Marchió C, Reis-Filho J S. Nestin is expressed in basal-like and triple negative breast cancers. J Clin Pathol 2008;61:1045-50.

40. Mokrý J, Nemecek S. Angiogenesis of extra- and intraembryonic blood vessels is associated with expression of nestin in endothelial cells. Folia Biol (Praha) 1998;44:155-61. 